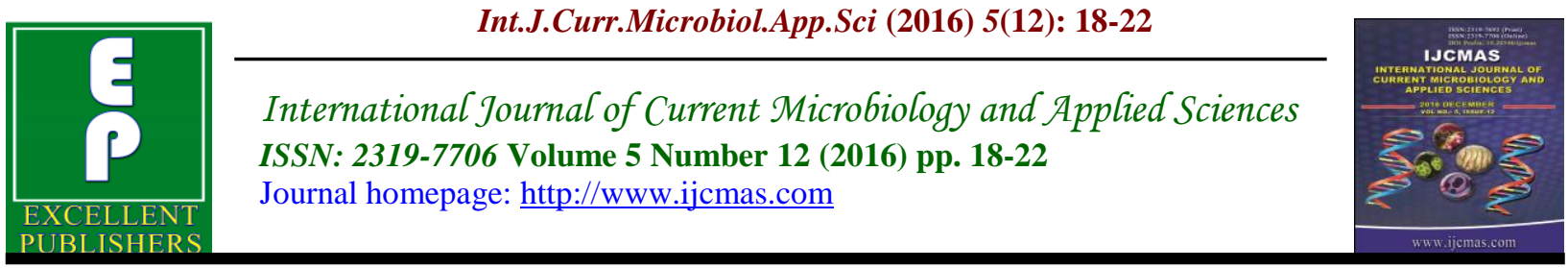

Original Research Article

http://dx.doi.org/10.20546/ijcmas.2016.512.003

\title{
A Study on the Etiological Trends and Antibiogram of Lower Respiratory Tract Infections (LRTIs) at a Tertiary Care Hospital
}

\author{
K.N. Ravichitra* and S. Subbarayudu \\ Department of Microbiology, ASRAM Medical College, Eluru -534005, \\ West Godavari Dist, Andhra Pradesh, India \\ *Corresponding author
}

Keywords

Lower respiratory tract infections, Gram negative bacilli, MRSA.

\section{Article Info}

Accepted:

08 November 2016 Available Online: 10 December 2016

\section{A B S T R A C T}

Lower respiratory tract infections are among the most common infectious diseases of humans worldwide and continue to be a major cause of morbidity. This study focused on determining the microbial agents of lower respiratory tract infections and the susceptibility profile of bacterial isolates. A total of 585 samples provisionally diagnosed as suffering from lower respiratory tract infections were collected and subjected to microbiological investigations. Out of 585 samples, 345 $(58.9 \%)$ showed growth of various bacteria. Gram negative bacteria constituted $65.5 \%$ of isolates where as gram positive bacteria accounted for $34.5 \%$ of the isolates. Klebsiella species was the predominant isolate followed by Staphylococcus aureus and other bacteria. A low level of antibiotic resistance was noted in our study. Of the 191 enterobacterial species, 62 (32.7\%) were ESBL producers and $9(3.9 \%)$ of gram negative bacteria were MBL producers. Majority of the MBL producers were nonfermenting gram negative bacilli. Among the gram positive bacterial isolates $25(22.5 \%)$ were MRSA strains. Majority of the antibiotic resistant strains were isolated from endotracheal tube secretions. Sensitivity to aminoglycosides and quinolones was good in our study. The present study reveals various pathogens involved in LRTI and their tendency towards antibiotic resistance.

\section{Introduction}

Infections of the upper and lower respiratory tract continue to be a major cause of morbidity and mortality throughout the world (Reid et al., 2010). Infections in the LRT usually occur when the infecting organisms reach the lower airways or pulmonary parenchyma by passing the mechanical and other non specific barriers of the upper respiratory tract (Dylan et al.,). Infection involving the lungs is called pneumonia or lower respiratory tract infection and is a common clinical problem in the practice of respiratory care. In the late 1800s, Sir William Osler remarked that pneumonia is 'captain of the men of death' because of its poor prognosis in the preantibiotic era. More than a century later, pneumonia remains a major cause of morbidity and mortality around the world. Five million people die from pneumonia 
worldwide each year. Pneumonia is the leading cause of death and the most common cause of infection-related mortality (Steven et al., 2009). Despite being the cause of significant morbidity and mortality, pneumonia is often misdiagnosed, mistreated, and underestimated.

Over the last decade or two, however patients presenting to the hospital have often been found to be infected with multidrugresistant (MDR) pathogens previously associated with hospital-acquired pneumonia. The potential involvement of these MDR pathogens has led to a revised classification system in which infection is categorized as either community-acquired pneumonia (CAP) or health care-associated pneumonia (HCAP), with subcategories of HCAP including hospital-acquired pneumonia (HAP) and ventilator-associated pneumonia (VAP) (Lionel, 2012). It is the second most common hospital acquired infection and leading cause of hospital acquired infection associated death.

The etiological agents of LRTIs vary from area to area and from time to time. Rapid diagnosis of the causative agent of respiratory tract infections is crucial in reducing morbidity and avoiding excessive and inappropriate antibiotic use which promotes the development of antimicrobial resistance. This study was undertaken to know the etiology and antimicrobial susceptibility pattern of LRTIs in our area.

\section{Materials and Methods}

This is a prospective study conducted over a period of 12 months from jan 2014 to dec 2014 at Department of Microbiology in a tertiary care teaching hospital. A total of 585 samples were collected from both inpatients and out patients, of all age groups and both sexes diagnosed provisionally as suffering from lower respiratory tract infections. Samples included 372 sputum, 49 bronchial wash, 101 endotracheal tube secretions and 63 pleural fluid. Samples were collected aseptically into well labeled sterile wide mouthed containers with screw caps and transported to the laboratory without delay.

\section{Bacteriology}

Films were made from the specimens and stained by Gram's method. Gram stain with $<10$ squamous epithelial cells and > 25 leucocytes / low power field (100 x magnifications) was subjected to cultural examination (Lionel et al., 2012).

Each sample was inoculated on blood, chocolate and MacConkey agar plates. The plates were incubated at $37{ }^{\circ} \mathrm{C}$ for $24-48$ hours. Emergent colonies were identified using standard methods (Elmer et al., 2006; Patricia et al., 2014).

\section{Antibiotic sensitivity testing}

Susceptibility tests were performed on all the bacterial isolates on Muller-Hinton agar by Kirby-Bauer disc diffusion according to CLSI guidelines. The commercial available antibiotic discs used for the study are Ceftriaxone, Ceftazidime, Azithromycin, Amikacin, Ofloxacin, Amoxyclav, cotrimoxazole, Vancomycin, Imipenem, Tobramycin, Piperacillin. Methicillin resistance was detected using Cefoxitin 30 $\mu \mathrm{g}$ disc according to CLSI guidelines

\section{Extended spectrum beta lactamase (ESBL) detection}

Was done by double disc diffusion method using Cefotaxime $30 \mu \mathrm{g} /$ disc and Cefotaxime and Clavulanate 30/10 $\mu \mathrm{g}$ disc were used according to CLSI guidelines 
Metallobeta-lactamase detection (MBL)

Modified Hodge Test (MHT) was performed for detection of MBL

\section{Results and Discussion}

Out of the 585 samples processed, 372 were sputum, 101 endotracheal aspirates, 49 bronchial wash and 63 were pleural fluid. Of the samples tested majority 429 (73.3\%) were inpatients and $156(26.7 \%)$ were outpatients. Of the samples processed 345 $(58.9 \%)$ showed growth of various bacteria. Distribution of the samples and their positivity is shown in the table-1

Isolation of gram negative bacteria was more frequent $(65.5 \%)$ than the gram positive organisms culture positivity was more in inpatients $77.9 \%$ in comparison to the outpatients $22 \%$. Klebsiella species was the predominant isolate recovered followed by Staphylococcus aureus, Coagulase Negative Staphylococci, Pseudomonas species, Escherichia coli, Enterococci, Acinetobacter and other enterobacterial species like Proteus, Citrobacter. Klebsiella species was the predominant gram negative organism and staphylococcus aureus was the predominant gram positive organism isolated. Among gram negative organisms enterobacteriaceae family predominated with 191 isolates $(55.4 \%)$ and non fermenters constituted $35(10.1 \%)$ of the isolates. Of the 191 enterobacterial species, $62(32.7 \%)$ were ESBL producers. Majority of the ESBL producers were the isolates from endotracheal tube secretions. 9(3.9\%) of gram negative bacteria were MBL producers. Majority of the MBL producers were nonfermenting gram negative bacilli.

Table.1 Distribution and positivity of the samples

\begin{tabular}{|l|c|c|c|}
\hline Samples & Total no & No of positives & \% of positives \\
\hline Sputum & 372 & 207 & 55.7 \\
\hline Bronchial wash & 49 & 30 & 61.2 \\
\hline ET tube secretions & 101 & 91 & 90.1 \\
\hline Pleural fluid & 63 & 17 & 26.9 \\
\hline
\end{tabular}

Table.2 Sensitivity of the isolates to commonly used antibiotics

\begin{tabular}{|l|c|c|c|c|}
\hline Antibiotics & $\begin{array}{c}\text { Klebsiella } \\
\text { S \% }\end{array}$ & $\begin{array}{c}\text { Staphylococcus aureus } \\
\text { S \% }\end{array}$ & $\begin{array}{c}\text { CONS } \\
\text { S \% }\end{array}$ & $\begin{array}{c}\text { Pseudomonas } \\
\text { S \% }\end{array}$ \\
\hline Ceftriaxone & 79.9 & 78.1 & 86.8 & 58.1 \\
\hline Ceftazidime & $70.4 \%$ & 72.6 & 76.3 & 83.9 \\
\hline Azithromycin & - & 63.0 & 68.4 & - \\
\hline Amikacin & $85.5 \%$ & 65.8 & 71.1 & 80.6 \\
\hline Ofloxacin & $75.5 \%$ & 94.5 & 73.7 & 77.4 \\
\hline Amoxyclav & 66.0 & 72.6 & 55.3 & - \\
\hline Cotriamoxazole & 66.7 & - & - & - \\
\hline Vancomycin & - & 87.7 & 84.2 & - \\
\hline Imipenem & 84.9 & - & - & 83.9 \\
\hline Tobramycin & - & - & - & 64.5 \\
\hline Piperacillin & - & - & - & 74.2 \\
\hline
\end{tabular}




\section{Chart 1}

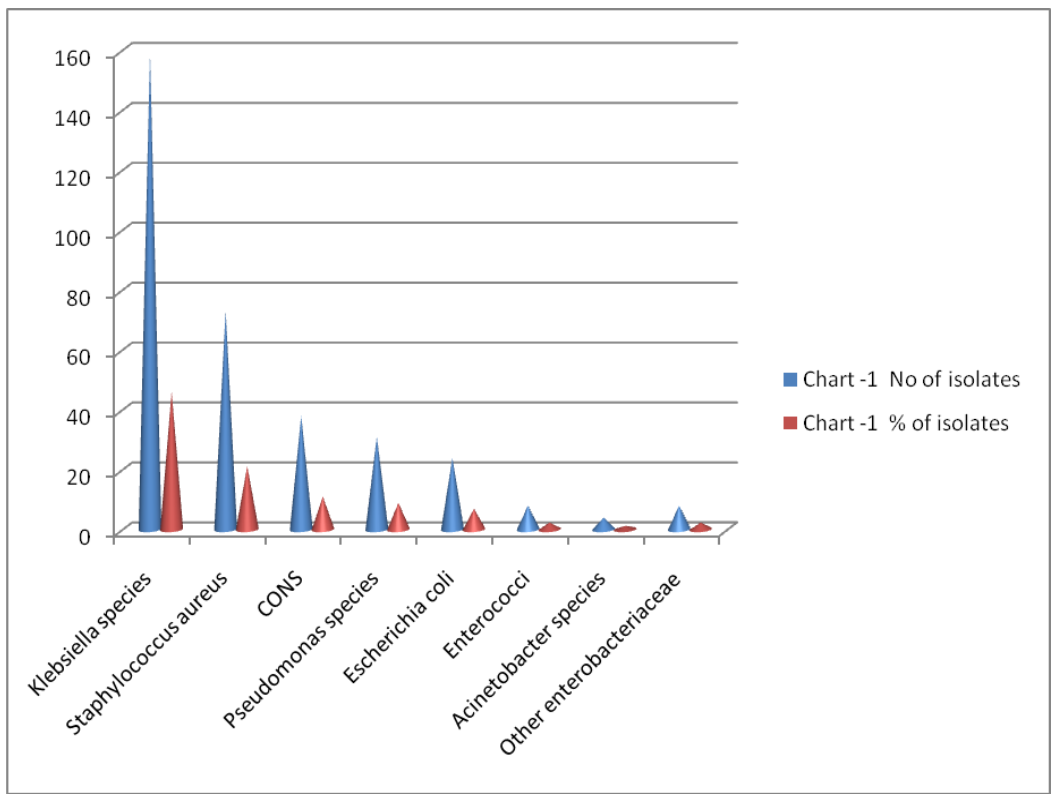

Among the gram positive bacterial isolates 25 (22.5\%) were MRSA strains. Of them 20 isolates belonged to Staphylococcus aureus and 5 isolates to Coagulase negative staphylococci. The antimicrobial susceptibility profile of bacterial isolates is shown in tabe-2. Imipenem and amikacin were found to show greater activity against gram negative bacterial isolates where as vancomycin, amikacin, ofloxacin were effective against gram positive isolates.

The etiological agents of LRTIs vary from area to area and from time to time. Management of LRTIs is a challenge due to the emergence of multi drug resistance. In the present study $58.9 \%$ of samples showed growth of different bacteria which is consistent with the study conducted by Banerjee et al., 2014. Our study showed that infection rate with gram negative bacilli $(65.5 \%)$ was higher than that of gram positive cocci (34.5\%) which is in accordance with a study conducted by Ruoxi et al., (2014) Our study showed Klebsiella species accounting for $46.1 \%$ of all the isolates was the predominant organism isolated followed by Staphylococcus aureus which is similar to the study conducted by Supriya panda et al., and Christopher Aye Egbe et al., (2011) MRSA strains in our study was $22.5 \%$ which is slightly higher than that reported by Ramana et al., (2014) ESBL producers in our study was $32.7 \%$ which is slightly higher than that reported by Tripathi puri et al., MBL producers in our study was $3.9 \%$ similar to the study conducted by Mishra Acharya et al., (2012). Our study also showed that majority of the resistant strains were from ET tube secretions similar to one indicated by Navaneeth et al., (2002). Present study showed susceptibility to aminoglycosides and fluroquinolones was good when compared to other drugs tested.

We conclude that gram negative bacilli were the predominant isolates of lower respiratory tract infection with Klebsiella species as the common isolate. Occurrence of ESBL's, MBLs, MRSA producing bacteria though low in our study, is a cause of concern. This study showed that isolates from ET tube secretions were found to be more drug 
resistant than isolates from other respiratory samples indicating higher antibiotic usage in the critical care units. We emphasize the need for prompt clinical diagnosis coupled with microbiological observations along with appropriate treatment strategies in the management of both community and nosocomially acquired LRTI's.

\section{References}

Banerjee, A., D. Pal, S. Pal, A. Naskar, et al. 2014. A study on prevalence and antibiotic sensitivity pattern of bacteria causing lower respiratory tract infections and their association with risk groups. $16^{\text {th }}$ International Congress on Infectious Diseases. Int. Society for Infect. Dis.

Christopher Aye Egbe et al. 2011. Microbiology of Lower Respiratory Tract Infections in Benin City, Nigeria. Malays. J. Med. Sci., 18(2): 27-31.

Dylan Slotar, James, L., Cook. 2010. Text book of Diagnostic Microbiology. $3^{\text {rd }}$ edition. Elsevier.

Elmer, W., Koneman, Stephen, D., Allen, Willian, M., janda, Paul, C., Schreckenberger and Washington, C., Winn. 2006. Color Atlas And Textbook Of Diagnostic Microbiology.6th edition. Baltimore: Lippincott Williams Wilkins.

Gerald collee, J., Andrew, G., Fraser, Barrie, P. Marmion and Anthony Simmons. 2012. Mackie \& Mc Cartney: Practical Medical Microbiology. 14th edition. Churchill Livingstone: Elsevier.

He, R., Luo, B., Hu, C., Li, Y., Niu, R. 2014. Differences in distribution and drug sensitivity of pathogens in lower respiratory tract infections between general wards and RICU. J. Thorac. Dis.,
6(10): $\quad$ 1403-1410. doi: 10.3978/j.issn.2072-1439.2014.09.22

Lionel, A., Mandell, Richard wunderink. 2012. Harrison's Principles of Internal Medicine. $18^{\text {th }} \quad$ edition.Mc GrawHill(Medical) companies.

Mishra, S.K., Acharya, J., Kattel, H.P., Koirala, J. Metallo-beta-lactamase Producing Gram-negative Bacterial isolates. J. Nepal Health Res. Counc., 10(22): 208-13.

Navaneeth, B.V., and M.R.Sandhya Belwadi.Antibiotic Resistance Among Gram -negative Bacteria of Lower Respiratory Tract Secretions in Hospitalized Patients. Indian J. Chest Dis. Appl. Sci., 44: 173-176.

Patricia, M., Tille. 2014. Bailey \& Scott's Diagnostic Microbiology. $13^{\text {th }}$ edition. Elsevier Mosby.

Ramana, K.V., et al. 2014. Aetiology and Antimicrobial Susceptibility Patterns of Lower Respiratory Tract Infections (LRTI) in a Rural Tertiary Care Teaching Hospital in Karimnagar, South India. American J. Infect. Dis. Microbiol., 1(5): 101-105.

Reid, P.T., J.A., Innes. 2010. Davidson's Principals and Practice of Medicine. $21^{\text {st }}$ edition. Churchill Livingstone Elsevier.

Steven, K., Schmitt, David, L., Long Worth. 2009. Egan's Fundamentals of Respiratory care. $9^{\text {th }}$ edition. Mosby Elsevier.

Supriya Panda, et al. 2012. Lower Respiratory Tract Infection-Bacteriological profile and antibiogram pattern. Int. J. Cur. Res., vol 04(21): 149-155.

Tripathi Purti, C., Dhote Kiran. 2014. Lower Respiratory Tract Infections: Current Etiological Trends and Antibiogram. $J$. Pharm. Biomed. Sci., 04(03): 249-255.

\section{How to cite this article:}

Ravichitra, K.N., and Subbarayudu, S. 2016. A Study on the Etiological Trends and Antibiogram of Lower Respiratory Tract Infections (LRTIs) at a Tertiary Care Hospital. Int.J.Curr.Microbiol.App.Sci. 5(12): 18-22. doi: http://dx.doi.org/10.20546/ijcmas.2016.512.003 